Çukurova Üniversitesi Mühendislik Mimarlık Fakültesi Dergisi, 32(4), ss. 185-192, Aralık 2017

\title{
EImas Telli Sayalama Makinesi Kullanılan Bir Doğaltaş Fabrikasında Ortam Şartlarının Değerlendirilmesi
}

\author{
Ali Ekrem ARITAN"1, Melek TÜMER ${ }^{1}$ \\ ${ }^{1}$ Afyon Kocatepe Üniversitesi, Mühendislik Fakültesi, Maden Mühendisliği Bölümü, \\ Afyonkarahisar
}

Geliş tarihi: 12.06 .2017

Kabul tarihi: 19.12 .2017

$\ddot{\mathbf{O z}}$

Ülkemiz Alp Kuşağı üzerinde yer aldığından doğaltaş rezervi (5,161 milyon $\left.\mathrm{m}^{3}\right)$ bakımından zengindir. Son yıllarda dünya genelinde doğaltaş kullanım oranları önemli derecede artış göstermektedir. Dünya ülkeleri ve Türkiye'de doğaltaş kullanımına artan talepten dolayı üretim hızlanmıştır. Buna bağlı olarak iç ortam kalitesinin sebep olduğu meslek hastalıklarının görülme olasılığı önem kazanmıştır. Bu çalışmada, elmas tel kesme makinesi ile kesim yapılan bir doğaltaş fabrikasında gürültü, aydınlatma ve termal konfor gibi fiziksel risk etmenlerinden olan bazı ortam şartları ölçümleri alınmıştır. Bu ölçümler mevcut standartlar ve yönetmeliklere bağlı olarak değerlendirilmiştir. Riskli olan çalışma koşulları için önlem olarak kişisel koruyucu donanımlar önerilmiştir.

Anahtar Kelimeler: Sayalama makinesi, Doğaltaş, İş sağlığı ve güvenliği

\section{Investigation of Environmental Conditions in a Natural Stone Factory using Monolamella Machine}

\begin{abstract}
Since our country is situated on the Alpine orogeny, it is rich in natural stone reserves $\left(5.161 \mathrm{million}^{3}\right)$. In recent years, natural stone utilization rates have increased considerably throughout the world. Production has been accelerated due to the increasing demand for natural stone usage in the world countries and Turkey. Accordingly, the possibility of occupational diseases caused by the quality of indoor environment has become important. In this study, some environmental conditions measurements, such as noise, lighting and thermal comfort, were taken from a natural stone factory which was cut with monolamella machine diamond wire cutting machine. These measurements have been evaluated based on existing standards and regulations. Personal protective equipment has been proposed as precautions for risky working conditions.
\end{abstract}

Keywords: Monolamella machine, Natural stone, Occupational health and safety

*Sorumlu yazar (Corresponding author): Ali Ekrem ARITAN, aritan@aku.edu.tr 


\section{GíRiş}

Dünya tarihinde insan toplulukları yerleşik hayata başladıklarından beri mekânlarda, yapılarda ve sanatsal tasarımlarda doğaltaşlar uygarlık simgesidir. Günümüzde de doğaltaşlar iç ve dış dekorasyonlarda, süs eşyası yapımında, kaldırım taşlarında ve dış cephe kaplama da yaygın olarak kullanılmaktadır.

Türkiye doğaltaş rezervleri bakımından dünya sıralamasında zengin ülkeler arasında yer almaktadır. Rezervlerimizin fazla olmasının sebebi Türkiye'nin dünya üzerinde bulunduğu coğrafi konumdur. Alp kuşağında yer alan Türkiye, mineral ve renk zenginliğine sahiptir. Marmara ve Ege başta olmak üzere tüm coğrafi bölgelerde doğaltaş rezervleri mevcuttur.

Türkiye, dünyanın doğaltaş rezervleri bakımından en zengin olan Alp kuşağında yer almaktadır. Türkiye'nin doğaltaş muhtemel rezerv toplamı 5,1 milyar $\mathrm{m}^{3}$ 'tür. $\mathrm{Bu}$ rezerv miktarı dünya rezervinin \%33'ünü oluşturmaktadır [1].

Son yıllarda doğaltaş madenciliğinde talebin artmasıyla birlikte üretim de artmıştır. Üretim hızı arttıkça kazalar ve meslek hastalıkları daha fazla görülmeye başlamıştır. Ülkemizde önem kazanması gereken iş sağlığı ve güvenliği konusunda çalışmalara devam edilmektedir. Çalışılan ortam koşullarının iyi olması çalışanların iş gücü verimliliğine doğrudan etki etmektedir. Çalışanların işlerine motive olabilmeleri için çalışma ortamı standart ve yönetmeliklere göre düzenlenmelidir.

Doğaltaş fabrikalarında sayalama, genellikle elmas telli sayalama makinesi ile yapılır. Bu makinenin bir çeşidi elmas telli kesme makinesinde olduğu gibi kesme işlemi elmas boncuklu tel yardımı ile makinenin ray üzerinde geriye doğru hareketi ile yapılırken soğutma yine su ile sağlanmaktadır.

Doğaltaş fabrikalarında elmas tel kesme makinesi ile blok ebatlama işlemi esnasında gürültü, termal konfor ve aydınlatma, çalışanların meslek hastalığına yakalanmasına sebep olmaktadır. Bu tehlikeler ile ilgili standartlar referans alınarak ölçümler ve değerlendirmeler yapılmalıdır. Oluşan risklere karşı önlemler alınarak kişisel koruyucu donanımlar önerilmelidir. Fabrikada sulu kesim yapıldığı için eser miktarda toz oluşmaktadır. Blok ebatlama esnasında makinede oluşan titreşim ile ilgili çalışanlarda kişisel maruziyet oluşmamaktadır. Ayrıca kesim sırasında kesilen kayacın firlaması, tel kayması-kopması vb. etkenler, makine ile insan arasina konulan paravan vasıtası ile engellenmiştir.

\section{GENEL BİLGILER}

\subsection{Aydinlatma}

Uluslararası Aydınlatma Komisyonu (CIE), aydınlatmayı; "Nesnelere, çevrelerine ve ufak ya da büyük bölgelere, bunların görülebilmesi için, 1şık uygulamak." olarak tanımlamaktadır [2]. Doğaltaş fabrikalarında yapılan işin gereği çalışanların detaylı çalışmasından dolayı aydınlatmanın son derece iyi olması amaçlanmalıdır.

Bir doğaltaş fabrikasında aydınlatma, çalışanların yaş ortalamalarına, göz fonksiyonlarının sağlık durumuna ve yapılan işin niteliğine bağlı olarak ayarlanmalıdır. Aydınlatmanın iyi yapıldığı bir fabrikada, kaza riski, mesleki hastalıklar ve üretim kayıpları en aza indirilmiş olur.

Doğaltaş fabrikalarında iyi bir aydınlatma sistemine sahip olunmak istendiğinde dikkat edilmesi gereken özellikler şunlardır;

- Aydınlatma şiddeti yeterli olmalı,

- Aydınlatma bütün alana eşit yayılmalı,

- Işık yönü ve gölgelemeye dikkat edilmeli,

- Işık yansımalarından kaçınılmalı,

- Kullanılan ışığın niteliği uygun olmalı,

- Titreşim ve parlaklık değişmelerini engellemek için aydınlatma sabit olmalı,

- İşyerlerinde yansıma ve psikolojik etki açısından uygun renkler seçilmelidir [3].

\subsection{Gürültü}

Herhangi bir maddenin titreşmesi sonucu meydana gelen titreşimin hava, sıvı veya gaz ortamda 
yayılması ile ortaya çıkan enerji dalgasına ses denir [4]. Sesin niteliğini frekans ve şiddet olmak üzere iki özelliği belirlemektedir. Sesi meydana getiren saniyedeki titreşim sayısı frekans ile ifade edilmekte ve Hertz $(\mathrm{Hz})$ ile birimlendirilmektedir. Ses dalgasının içerdiği enerjinin birim alandaki enerjiye oranına ise, şiddet denilmektedir. Sesin şiddet birimi desibel'dir ve (dB) şeklinde gösterilir. Ses dalgalarının şiddeti ve yoğunluğu gürültü düzeyini belirlemektedir. Gürültünün şiddeti ise $\mathrm{dB}$ (desibel) birimi ile ölçülmektedir [5].

Endüstrideki gürültü ise çalışanlarda fizyolojik ve psikolojik etkiler bırakan, işitme düzeyini ve sağlığına olumsuz yönde etki eden ve iş verimini düşüren seslerdir $[6,7]$.

2013 yllında Resmi Gazete'de yayınlanan "Çalışanların Gürültü İle İlgili Risklerden Korunmaları Dair Yönetmelik" de verilen maruziyet eylem değerleri ve maruziyet sınır değerleri Çizelge 1'de verilmiştir [8].

Çizelge 1. Gürültü maruziyet değerleri

\begin{tabular}{|l|c|}
\hline $\begin{array}{l}\text { En düşük maruziyet eylem } \\
\text { değerleri: }\left(\mathrm{L}_{\mathrm{EX}, 8 \text { saat }}\right)\end{array}$ & $80 \mathrm{~dB}(\mathrm{~A})$ \\
\hline $\begin{array}{l}\text { En yüksek maruziyet } \\
\text { eylem değerleri: }\left(\mathrm{L}_{\mathrm{EX}, 8 \mathrm{saat}}\right)\end{array}$ & $85 \mathrm{~dB}(\mathrm{~A})$ \\
\hline $\begin{array}{l}\text { Maruziyet sınır değerleri: } \\
\left(\mathrm{L}_{\mathrm{EX}, \text { 8saat }}\right)\end{array}$ & $87 \mathrm{~dB}(\mathrm{~A})$ \\
\hline
\end{tabular}

Gürültü ölçümleri yapılırken; ölçülecek gürültünün niteliği, maruziyet süresi ve çevresel faktörler göz önünde bulundurulmalıdır. Maruziyetin önlenmesi ve azaltılması için şu tedbirler alınmalıdır;

- Gürültüye maruziyetin daha az olduğu başka çalışma yöntemlerinin seçilmesi,

- Yapılan işe göre mümkün olan en düşük düzeyde gürültü yayan uygun iş ekipmanının seçilmesi,

- İşyerinin ve çalışılan yerlerin uygun şekilde tasarlanması ve düzenlenmesi,

- İş ekipmanını doğru ve güvenli bir şekilde kullanmaları için çalışanlara gerekli bilgi ve eğitimin verilmesi,
- Gürültünün teknik yollarla azaltılması ve bu amaçla;

$\checkmark$ Hava yoluyla yayılan gürültünün; perdeleme, kapatma, gürültü emici örtüler ve benzeri yöntemlerle azaltılması,

$\checkmark$ Yapı elemanları yoluyla iletilen gürültünün; yalıtım, sönümleme ve benzeri yöntemlerle azaltılması,

- İşyeri, işyeri sistemleri ve iş ekipmanları için uygun bakım programlarının uygulanması,

- Gürültünün, iş organizasyonu ile azaltılması ve bu amaçla;

$\checkmark$ Maruziyet süresi ve düzeyinin sinırlandirılması,

$\checkmark$ Yeterli dinlenme aralarıyla çalışma sürelerinin düzenlenmesi [8].

\subsection{Termal Konfor}

Termal konfor, kişinin bulunduğu ortam ile etkileşiminden duyduğu memnuniyet veya memnuniyetsizliktir. Bu memnuniyet; hava hızı, nem, radyant 1s1, havanın sıcaklığı gibi çevresel faktörler ve metabolik hız ve giysi yalıtımı gibi kişisel faktörlere bağlıdır. Vücudun termal dengesi, vücudun üretilen iç $1 \mathrm{~S} 1$ enerjisinin, kaybedilen 1S1 enerjisine eşit olması durumunda ortaya çıkar [9].

Türkçe anlamı tahmini ortalama oy olan PMV (Predicted Mean Vote); insan vücudunun termal dengesine dayanan ve büyük bir insan test grubundaki 7 seviyeli termal duyarlılık ölçeğindeki deneylerden türetilen ortalama bir karar değerini tahmin eden bir indekstir. Bu 7 seviyeli termal duyarlılık ölçeği Çizelge 2'de verilmektedir [10].

Çizelge 2. Sıcaklık duyarlılığı ölçeği

\begin{tabular}{|c|l|l|}
\hline PMV & Anlam & Yorum \\
\hline+3 & Aşırı sıcak & Kabul edilemez, sıcak \\
\hline+2 & Sıcak & Çok sıcak \\
\hline+1 & Hafif sıcak & Kabul edilebilir, sıcak \\
\hline 0 & Nötr & Konforlu \\
\hline-1 & Hafif serin & Kabul edilebilir, serin \\
\hline-2 & Serin & Çok serin \\
\hline-3 & Soğuk & Kabul edilemez, soğuk \\
\hline
\end{tabular}


Yaş hazne küre sıcaklı̆̆ı (WBGT) indeksi, bir kişinin maruz kaldığ 1 1Sı baskısını gösteren deneysel indekslerden birisidir. Bu indeksin, endüstriyel bir ortamda belirlenmesi kolaydır. Bu indekse göre değerlendirilen metot, çok kesin bir indeks kullanma isteği ile kontrol ölçümlerinin endüstriyel bir ortamda kolayca uygulayabilme ihtiyacı arasında bir uzlaşmadır ve açıklayıcı bir metot olarak dikkate alınmalıdır [11].

İnsan ve ortam arasındaki 1Sı değişim analizine bağlı olarak termal baskıyı tahmin eden metot, çok kesin bir baskı tahminine ve korunma metotlarıyla ilgili bir analize izin verir. Fakat mevcut ölçüm teknolojisiyle metot, girişimin çok uzun zaman alması ve zor olmasıyla ilgili dezavantaja sahiptir. Böyle bir metot ya sıcak ortamda yoğun çalışma şartları için bir analizin yapılması arzu edildiğinde doğrudan kullanılacak veya ilk yaklaşımdan elde edilen değerler, belirtilen referans değerlerini geçtiğinde WBGT indeksine dayanan metoda ilave olarak kullanılacaktır [11]. WBGT 1sı stres indeksi için referans değerler Çizelge 3 'de verilmektedir.

Çizelge 3. Belirlenen bir duruma karşılık gelen referans değerler [11]

\begin{tabular}{|c|c|c|}
\hline $\begin{array}{c}\text { Metabolik } \\
\text { Oran } \\
\text { Sinıfi }\end{array}$ & \multicolumn{2}{|c|}{ Metabolik Oran $(\mathrm{M})$} \\
\hline & $\begin{array}{c}\text { Bir birim } \\
\text { deri yüzey } \\
\text { alanıyla ilgili } \\
\left(\mathrm{W} / \mathrm{m}^{2}\right)\end{array}$ & $\begin{array}{c}\text { Toplam }\left(1,8 \mathrm{~m}^{2} \text { 'lik }\right. \\
\text { deri yüzey alanı } \\
\text { için })(\mathrm{W})\end{array}$ \\
\hline 0 & $\mathrm{M} \leq 65$ & $\mathrm{M} \leq 117$ \\
\hline 1 & $65<\mathrm{M}<130$ & $117<\mathrm{M}<234$ \\
\hline 2 & $130<\mathrm{M} \leq 200$ & $234<\mathrm{M} \leq 360$ \\
\hline 3 & $200<\mathrm{M} \leq 260$ & $360<\mathrm{M} \leq 468$ \\
\hline 4 & $\mathrm{M}>260$ & $\mathrm{M}>468$ \\
\hline
\end{tabular}

\section{MATERYAL VE YÖNTEM}

\subsection{Materyal}

$\mathrm{Bu}$ çalışma 2017 yılında, Afyonkarahisar ili İscehisar ilçesinde bulunan doğaltaş fabrikasında, rampalı elmas tel kesme (blok ebatlama) makinesi ile Denizli travertenin kesimi esnasında ortam ölçümlerinden aydınlatma, termal konfor ve gürültü ölçümleri alınarak yapılmıştır.

Mermer ocağında blok ebatlamada kullanılan; motor gücü $15 \mathrm{~kW}$ ve $1450 \mathrm{~d} / \mathrm{d}$ özelliğinde elektrik motor tahrikli bir mile $44 \mathrm{~cm}$ çapında kasnağa bağlı mekanik sistemden oluşan rampalı elmas tel kesme (blok ebatlama) makinesi kullanılmıştır. Blok ebatlama makineleri ile gerek ticari blok üretimi gerekse ana kayaçtan ayrılan kütlenin dilimlenme işlemi yapılmaktadır. Blok ebatlama makinesi gövde, rampalı ray, kumanda panosu ve tekerleklerden oluşmaktadır.

Doğaltaş fabrikasında blok ebatlama esnasında kullanılan elmas tel kesme makinesi Şekil 1'de verilmiştir. Bunlar eğimli bir rampadan geriye ve aşağıya doğru makinenin kendi ağırlığ ilerlemesi prensibine dayanır. Geriye doğru olan harekete bağlı olarak gergin tutulan elmas boncuklu tel, su yardımı ile de bloku keser [12].

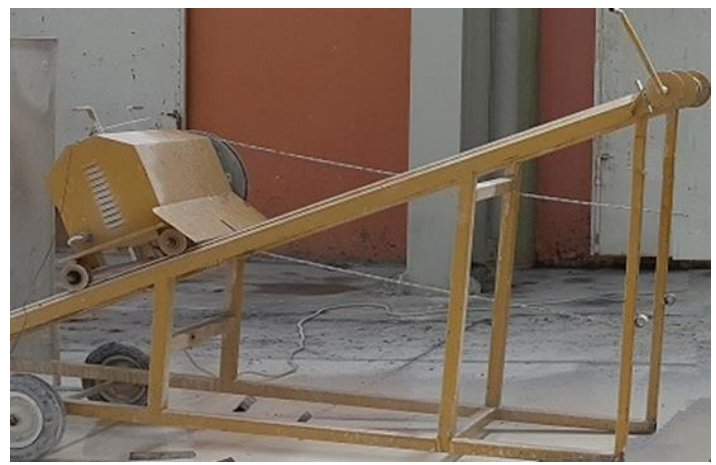

Şekil 1. Rampalı sayalama makinesi

\subsection{Yöntem}

Doğaltaş fabrikasında aydınlatma ölçümleri TS EN 12464-1 standardına göre HD 2102.2 cihazı ile yapılmış ve aynı standart çerçevesinde değerlendirilmiştir [13].

Elmas tel kesme makinesi kullanılarak sulu kesim yapılan fabrikada termal konfor ölçümleri, DELTA OHM WBGT 32.3 cihazı ile TS EN 27243, TS EN ISO 7730 standartlarına göre yapılmıştır. PMV hesaplaması için gerekli değerler ise ASHRAE 
55 'den alınmıştır. Sonuçlar Fanger modeline göre değerlendirilmiştir $[11,14,15]$.

Blok ebatlama esnasında ortamda alınan gürültü ölçümleri Testo 815 cihazı ve TS 2607 ISO 1999 standardı kullanılarak özel problar ile ölçümler alınmış ve değerlendirilmiştir [16].

\section{BULGULAR}

Doğaltaş fabrikasında, sayalama işlemi sırasında ortam gün 1şı̆̆ından faydalanılarak (1şığın pencere ve kap1 gibi boşluklar yardımıyla içeri girmesiyle sağlanan) doğal aydınlatma ile aydınlatılmaktadır. $\mathrm{Bu}$ ortamdan alınan aydınlatma ölçümlerinin ortalaması ise 3173 lüks'dür (Çizelge 4).

Çizelge 4. Aydınlatma ölçüm değerleri

\begin{tabular}{|l|c|}
\hline & $\begin{array}{c}\text { Aydınlatma ölçümü } \\
\text { (lüx) }\end{array}$ \\
\hline Max & 3672 \\
\hline Min & 2674 \\
\hline Ortalama & 3173 \\
\hline
\end{tabular}

Doğaltaş fabrikasında elmas telli sayalama makinesinin çalışması esnasında ortamda oluşan gürültü için cihazda ölçülen en yüksek değer 86,9 $\mathrm{dB}(\mathrm{A})$ 'dır.

Elmas tel kesme makinesinin sulu kesimi esnasında, termal konfor ölçümlerine ait hava hızı, çalışma sıcaklığı ve nem değerleri alınmıştır. Giysi 1sıl direnci ve metabolik oran, çalışma yeri göz önüne alınarak ANSI-ASHRAE 55-2010 standardına göre kabul edilmiştir (Çizelge 5) [15]

Çizelge 5. Termal konfor ölçüm ve kabul değerleri

\begin{tabular}{|l|c|c|c|c|c|}
\hline Konum & $\begin{array}{c}\text { Hava } \\
\text { hız1 } \\
(\mathrm{m} / \mathrm{sn})\end{array}$ & $\begin{array}{c}\text { Sicaklık } \\
\left({ }^{\circ} \mathrm{C}\right)\end{array}$ & $\begin{array}{c}\text { Nem } \\
(\%)\end{array}$ & $\begin{array}{c}\text { Giysi } \\
\text { 1s1l } \\
\text { direnci } \\
\mathrm{I}_{\mathrm{cl}}(\mathrm{clo})\end{array}$ & $\begin{array}{c}\text { Meta- } \\
\text { bolik } \\
\text { oran } \\
(\mathrm{met})\end{array}$ \\
\hline 1. Bölge & 2,31 & 22,7 & 40,4 & 0,96 & 1 \\
\hline 2. Bölge & 3,59 & 24,9 & 41,4 & 0,96 & 1 \\
\hline 3. Bölge & 0,50 & 20,3 & 33,8 & 0,96 & 1 \\
\hline 4. Bölge & 1,39 & 20,0 & 38,2 & 0,96 & 1 \\
\hline 5. Bölge & 1,20 & 19,9 & 36,0 & 0,96 & 1 \\
\hline
\end{tabular}

$\mathrm{Bu}$ değerler PMV metodu kullanılarak yorumlanmış ve elde edilen sonuçlar Çizelge 6'da verilmiştir.

Çizelge 6. PMV değerleri

\begin{tabular}{|l|c|}
\hline Bölge & PMV \\
\hline 1. Bölge & $-1,36$ \\
\hline 2. Bölge & $-0,84$ \\
\hline 3. Bölge & $-1,51$ \\
\hline 4. Bölge & $-2,08$ \\
\hline 5. Bölge & $-2,07$ \\
\hline
\end{tabular}

PMV metodu kullanılarak oluşturulan grafikler Şekil 2'de verilmiştir.
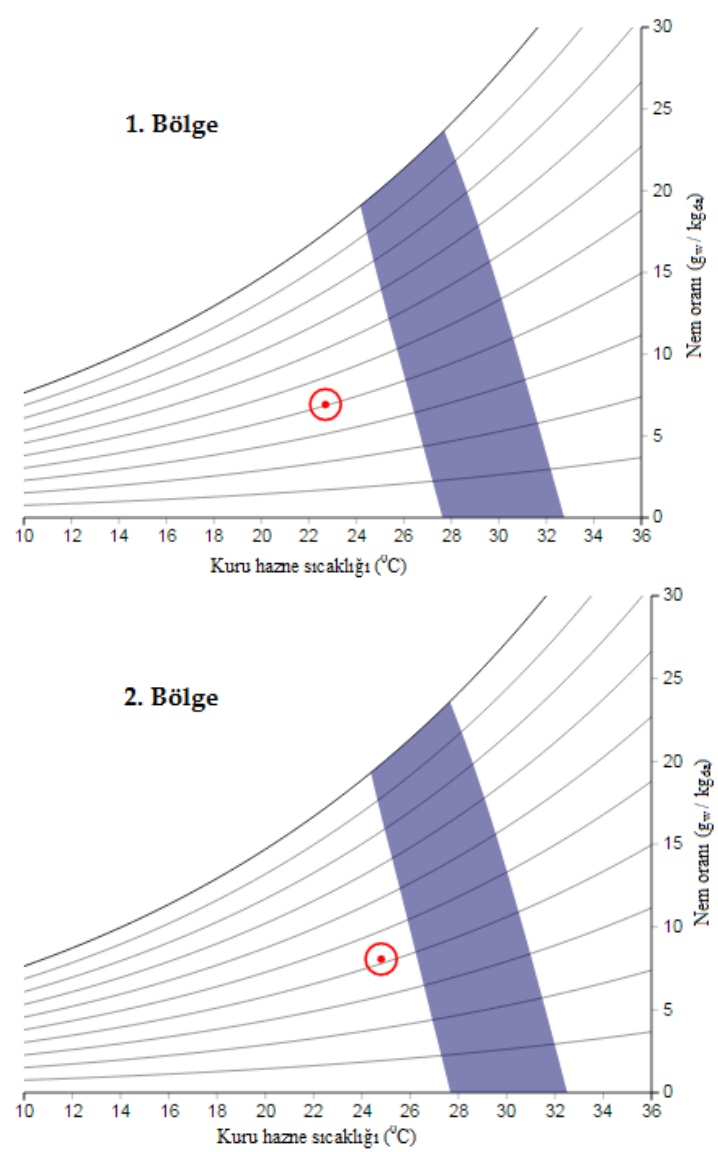

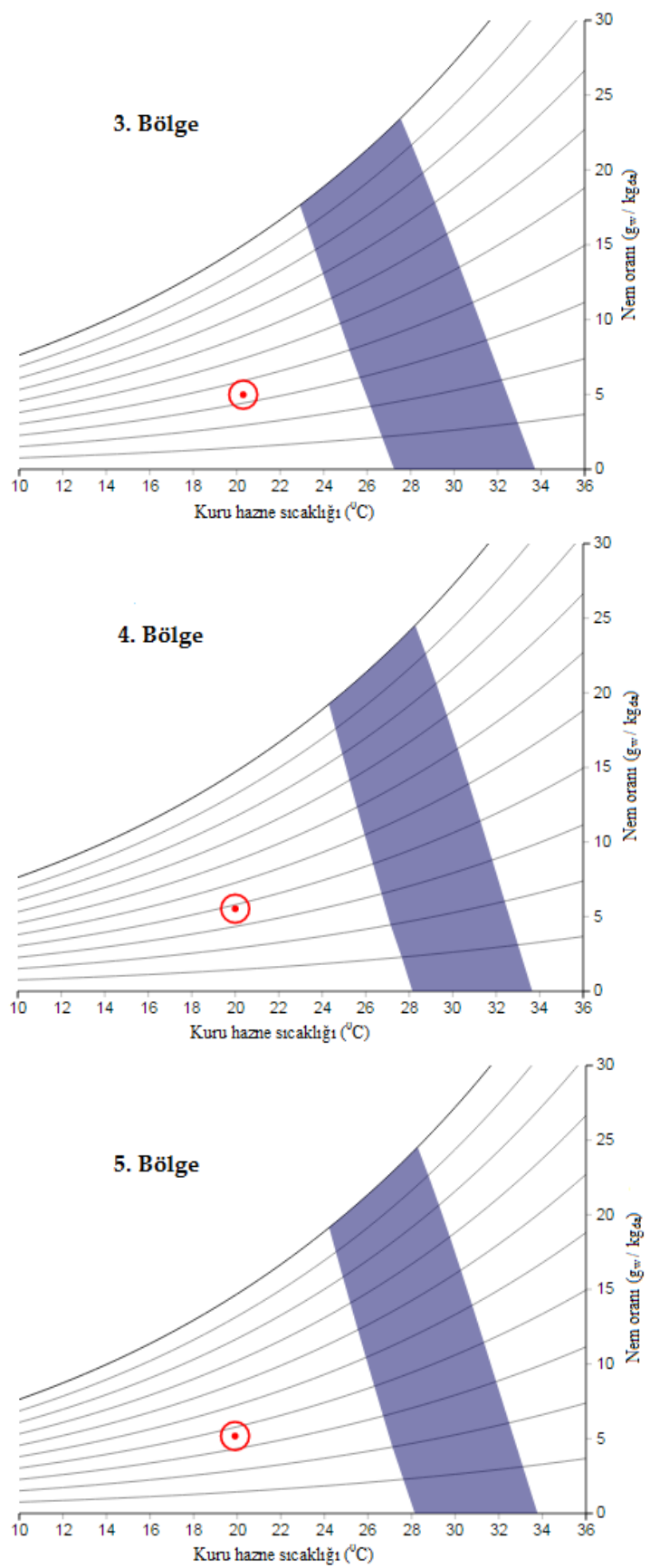

Şekil 2. Termal konfor ölçüm sonuçları [17]

$\mathrm{Bu}$ sonuçlara göre 1. ve 3. bölge kabul edilebilir serin durumdadır. 2. bölge termal konfor açısından konforlu alana en yakın değer olsa da kabul edilebilir serin ortam vardir. 4 . ve 5 . bölgelerdeki değerler birbirine yakın olup çok soğuktan aşırı soğuk konumuna geçme eğilimindedir ki termal konfor açısından en uygunsuz bölge bu ikisidir.

\section{SONUÇLAR}

Doğaltaş fabrikasında alınan aydınlatma ölçümlerinin ortalamasında aydınlatmanın yeterli olduğu görülmüştür. Gürültü ölçümlerinin ortalaması maruziyet sınır değerine yakın olup çalışanların kişisel koruyucu donanım kullanması zorunlu hale gelmiştir.

Elmas telli sayalama makinesinin çalışması esnasında alınan termal konfor ölçümlerinin PMV yöntemiyle hesaplanması sonucunda;

1. Bölgede alınan veriler de hava hızı yüksek, hava sıcaklığı düşük olduğundan PMV değeri eksiye düşerek kabul edilebilir serin ile çok serin konumu arasında yer almaktadır.

2. Bölgede hava hızı yüksek olduğundan PMV değeri konforlu bölgeden kabul edilebilir serin bölgesine doğru yaklaşmaktadır.

3. Bölgede hava sıcaklığının düşük olmasından kaynaklı PMV değeri eksi bölgede ve kabul edilebilir serin ortam oluşmuştur.

4. ve 5. bölgelerde hava sıcaklığının düşük olmasından kaynaklı PMV değeri düşük çıkmış çok serin olarak nitelendirilmektedir.

Yapılan bu çalışmada termal konfor ile ilgili problemlerin hem hava hızı hem de sicaklık ile doğrudan ilişkili olduğu görülmüştür. Ölçüm alınan tüm bölgelerde yapılan değerlendirmeler sonucunda kişisel koruyucu donanım kullanma zorunluluğu ortaya çıkmaktadır. Soğuğa karş1 alınacak önlemler; uygun giysiler kullandırılmalı, baretlerin içi; kulakları, alnı ve hatta gerekirse ağzı da kapatabilecek türde kapüşonlu ve muflonlu olmalıdır. Ayrıca kullanılan iş eldivenleri soğuğa karşı uygun yalıtımı ve izolasyonu sağlamalıdır [18]. Özellikle 4. ve 5. bölgelerde ortam şartları yeniden gözden geçirilmelidir. 
Doğaltaş fabrikasında alınan gürültü ölçüm sonuçları değerlendirildiğinde çalışanların sağlı ̆̆ risk altında olduğu görülmüştür. Çalışanlar gürültüye uzun süre maruz kalmaları durumunda meslek hastalıklarının görülme olasılığı artacaktır. Meslek hastalıklarını önlemek amacıyla çalışanlar uyarıcı levhaları ile uyarılmalı ve kulak tıkacı/kulaklık kullanmalıdırlar.

\section{KAYNAKLAR}

1. Türkiye Cumhuriyeti Ekonomi Bakanlığ1, 2016. Doğaltaş Sektör Raporu, Ankara, 1-2 s.

2. ISO, 8995. CIE S008/E - Lighting of Indoor Workplaces.

3. Aydemir, E., 1995. İş Veriminin Artırılması Bakımından Matbaa İşletmelerinde Ergonomi, 5. Ulusal Ergonomi Kongresi, Milli Prodüktivite Merkezi Yayınları, Yayın No: 495, İstanbul.

4. Bell, A., 1966. Noise: An Occupational Hazard And Public Nuisance, World Health Organization, 61-62, Geneva,.

5. Akbulut, T., 1996. İşçi Sağlığı Prensip ve Uygulamaları, 5. Baskı, Sistem Yayıncılık, 12 46, İstanbul.

6. Erkan, N., 1995. Ergonomi. Verimlilik, Sağlık ve Güvenlik İçin İnsan Faktörü Mühendisliği. MPM Yayınları: 373. Genişletilmiş İkinci Basım, Mert Matbaası, Ankara.

7. Çandır, M., 1996. Gürültü. Mühendis ve Makine. TMMOB Makine Mühendisleri Odası Aylık Yayın Organı. Çalışma Güvenliği Özel Say1, 37(435): 29-32.

8. Çalışanların Gürültü ile İlgili Risklerden Korunmalarına Dair Yönetmelik, 2013. 28721 Sayılı Resmî Gazete.

9. Arıtan, A.E., Şensöğüt, C., Ören, Ö., Tümer, M., 2016. Kırmataş Tesislerinde Çalışanların Maruz Kaldığı Fiziksel Risk Etmenleri, 8.Uluslararası Kırmataş Sempozyumu, Kütahya.

10. Yiğit, O.Ş., 2016. Heat Stress, Thermal Exposure and Comfort, Ambient Noise and Level of Illumination on Workplaces; Analysis of Measurement Techniques Within the Scope of Workplace Safety, 12. Uluslararası HVAC + Ar \& Ge Sanayii Sempozyumu, İstanbul.
11.TS EN 27243 Nisan 2002. Sicak OrtamlarWBGT (Yaş-Hazne Küre Sıcaklığı) İndeksine Göre Isının Çalışan Üzerindeki Baskısının Tahmini. Türk Standartları Enstitüsü, Ankara.

12. MEGEP, 2011. Blok Ayırma ve Ebatlama, Makine Teknolojisi, Ankara.

13. TS EN 12464-1 Şubat 2013. Işık ve Aydınlatma-Çalışma Yerlerinin Aydınlatılması -Bölüm 1: Kapalı Çalışma Alanları. Türk Standartları Enstitüsü, Ankara.

14. TS EN ISO 7730 Nisan 2006. Orta Dereceli Termal Ortamlar-PMV ve PPD İndislerinin Tayini Termal Rahatlık İçin Şartların Belirlenmesi. Türk Standartları Enstitüsü, Ankara.

15. ASHRAE, ANSI/ASHRAE Standard 55, 2010. Thermal Environmental Conditions for Human Occupancy, ASHRAE Publications.

16. TS 2607 ISO 1999 Nisan 2015. Akustik-İş Yerinde Maruz Kalınan Gürültünün Tayini ve Bu Gürültünün Sebep Olduğu İşitme Kaybının Tahmini. Türk Standartları Enstitüsü, Ankara.

17. Erişim tarihi: 09 Mayıs 2017. www.smap.cbe.berkeley.edu/comforttool

18. Arıtan, A.E., Tümer, M., Şensöğüt, C., 2017. Yeraltı Kömür Ocaklarında Termal Konfor Şartlarının İncelenmesi, Uluslararası Maden İşletmelerinde İşçi Sağlığı ve İş Güvenliği Sempozyumu 2017, Adana. 
